\title{
Coordinación educativa escuela-familia. Dificultades y soluciones
}

\section{Family-school coordination. Difficulties and solutions}

\author{
María Luisa García, Natalia Paíno \\ Universidad de Salamanca (España)
}

\begin{abstract}
Resumen
La visión que actualmente se tiene del profesorado ha cambiado. Ha decrecido el respeto a la figura docente y a su papel educativo en la vida infantil. Esta apreciación justifica dificultades en la relación Escuela-Familia. Con esta indagación se buscan propuestas para alcanzar la armonía y la coordinación fructífera entre ambas instituciones educadoras. Entre ellas, que sociedad, Escuela y familias se mentalicen de que realmente es necesario y urgente un nuevo viraje para continuar avanzando en este largo y difícil camino, lleno de soluciones esperanzadoras, puesto que Escuela y Familia son dos mundos llamados a trabajar en común (Bolívar, 2006).

Palabras clave: escuela-familia, coordinación educativa, dificultades, soluciones
\end{abstract}

\section{Abstract}

There is an obvious change in the way teachers are viewed. Respect has decreased and teachers' role is seen to be less relevant. This fact justifies the existing difficulties in family-school relations. This paper seeks proposals to reach harmony between the two educational institutions. It is crucial that the society in general, families and schools realize the necessary reforms that have to be taken into force to continue progressing since school and families are two worlds that need to work together (Bolívar, 2006)

Keywords: school-family, educational coordination, difficulties, solutions

\section{Método}

Se aborda una indagación mediante metodología cualitativa, valorada como la más oportuna por su flexibilidad y su gran riqueza de resultados. La recogida de datos se realiza mediante entrevistas a maestros/as y a familias de estudiantes de 3 a 6 años, que son transcritas. Se reducen los datos, categorizándolos y codificándolos en un árbol de indización que se utiliza como instrumento de análisis. Se contrastan mediante doble análisis para garantizar la fiabilidad. Se tratan con criterio ético, asegurando la confidencialidad de informantes. Brindan una proyección de la situación actual de las relaciones, desde ambas perspectivas, en el contexto estudiado: dos provincias del oeste de España.

\section{Resultados}

Los datos quedan distribuidos en las siguientes categorías: "Importancia, "Niveles de participación", "Calidad", "Dificultades", "Soluciones" y "Visión de la figura del/de la maestro/a". A continuación se expone una figura donde aparecen representadas las categorías citadas anteriormente, junto con el porcentaje total que corresponde a cada una de ellas.

Distribución total de las categorías

口

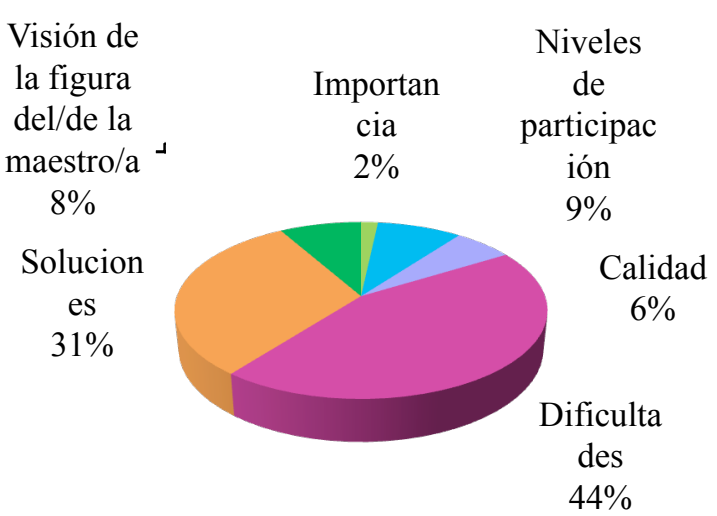

Figura 1. Distribución total de las categorías. Fuente: Elaboración propia.

Únicamente dos informantes hablaron sobre la importancia de la relación Escuela-Familia, considerándola muy importante. Todas las personas, excepto una, se refirieron a los niveles de participación. El nivel más considerado ha sido el de intercambio de información. Respecto a dicho nivel, un/a informante menciona una novedosa modalidad de comunicación Escuela-Familia utilizando las actuales tecnologías. Consiste en una plataforma educativa online donde el/la maestro/a escribe diariamente la información más relevante de ese día sobre el/la niño/a y las familias pueden leerlo.

Los datos sobre "Calidad" en la relación EscuelaFamilia confirman que la mayoría tiene una buena relación, bien con el/la maestro/a o bien con las familia; excepto dos personas: una de ellas describe una relación "regular" con el/la maestro/a y otra una "mala" relación caracterizada por la falta de implicación de la maestra. 
Como puede observarse, "Dificultades" y "Soluciones" acumulan el 75\% de los datos.

En la figura 2 y tabla 1 puede verse que la mayor parte de las dificultades de las que han hablado las personas que han sido entrevistadas son por parte de las familias, representando el $77 \%$ de los datos totales, mientras que las dificultades por parte de la Escuela representan el $23 \%$.

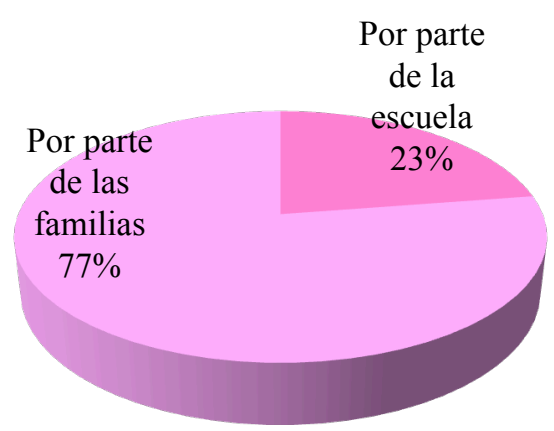

Dificultades en las relaciones Escuela-Familia

Figura 2. Distribución de la subcategoría "Dificultades". Fuente: Elaboración propia.

Tabla 1.

Frecuencias y porcentajes de la categoría "Dificultades". Fuente: Elaboración propia.

\section{CATEGORÍA 4: DIFICULTADES}

Subcategoría: Por parte de la Escuela

Frecuencia (Unidades Textuales): 35 Porcentaje: $23 \%$

Subcategoría: Por parte de las Familias

Frecuencia (Unidades Textuales): 120 Porcentaje: $77 \%$

Un docente ha destacado por insistir en las dificultades creadas por las familias, resumidas en una rotunda afirmación de que la Escuela nunca pone obstáculos para las buenas relaciones: "Desde luego, la Escuela, no" (u.t. 225). Otro docente, también desilusionado, afirma: "A algunos padres los he citado varias veces $\mathrm{y}$, unas veces por unas cosas y otras veces por otras, siempre ponen excusas...y no vienen" (u.t. 159-160). Se han recogido muchas más expresiones de este tipo y muy parecidas.

Sin embargo, la actitud del/la profesional que llevaba menos años trabajando era diferente: aunque expresaba las dificultades que la familia generaba, se mostraba menos descontento/a, mostrando una predisposición más abierta a relacionarse con las familias por diferentes vías y no solamente mediante el nivel de intercambio de información.

Las entrevistas realizadas a los/as maestros/as que más han hablado de "Dificultades" se han realizado en un colegio de clase social media-baja donde la mayor parte de las familias son de etnia gitana: "Las familias gitanas, en general, han cambiado mucho pero todavía tienen que mentalizarse más, implicarse más en el Proyecto Educativo Infantil porque...” (u.t. 333-335).
Algunos/as docentes exponen que su relación con las familias ha sido mejor cuando el centro educativo se encontraba en un contexto rural: "En los pueblos, yo, por mi experiencia, la Familia suele estar muy involucrada y el equipo directivo siempre suele contar con ellos para muchas actividades que se hacen tanto dentro como fuera del colegio" (u.t. 45-47).

Otros docentes mencionan los casos de padres separados que no se ponen de acuerdo en temas relacionados con la educación de sus hijos/as: "Por los temas de las familias desestructuradas que existen. La madre tiene un comportamiento y el padre tiene otro, $\mathrm{y}$ ahí, ¿qué hacemos" (u.t. 368-370).

Por último podría decirse que, como los tiempos han cambiado, también ha cambiado la visión que la sociedad y, en este caso, las familias, tienen sobre el/la maestro/a. De hecho, son varios los informantes que confirman dicha hipótesis: "No es que se confiara más, es que se tenía más respeto porque antes un profesor decía lo que fuera y es que iba a misa" (u.t. 63-64).“A las familias no se les ocurría en ningún caso llevarle la contraria a los docentes ni cuestionar su trabajo" (u.t. $552-553)$

\section{Discusión}

Como consecuencia del proceso seguido en la investigación, de las observaciones realizadas, de la habilidad para dialogar y de una buena actitud reflexiva, tras un profundo análisis de la información hallada, es posible ofrecer notables conclusiones generadas en el transcurso de la indagación.

Se dan coincidencias en reconocer que existen barreras (Dowling, y Pound, 1996), (García 1996). Los datos permiten deducir que la mayoría de las familias entrevistadas tienen una relación Escuela-Familia básica, sin llegar a implicarse en el centro educativo (Cabrera, Funes y Brullet, 2004). Parece necesario un mayor acercamiento Escuela-Familia que supere el nivel de relaciones e intercambio de información para alcanzar los otros dos niveles existentes: nivel de participación o de implicación y el nivel formativo.

La mayor parte de las personas informantes se han referido a "dificultades", particularmente a las dificultades generadas por las familias, por lo que podría deducirse que actualmente las familias originan mayores dificultades que la Escuela.

Los datos concluyen que ciertas dificultades estarían ligadas al contexto económico, social y cultural del centro, ya que la mayoría de cierto tipo de familias (p. e. de etnia) ponen obstáculos en su relación con la Escuela, mientras que la relación Familia-Escuela es más cercana y cordial, por parte de ambas instituciones, en los contextos rurales. Otra hipótesis acerca del origen de las dificultades en la relación es la existencia de familias desestructuradas.

La última hipótesis hace referencia a que las dificultades en la relación Escuela-Familia nacen porque actualmente se tiene una imagen social muy negativa del profesorado que contrasta mucho con la imagen que se tenía en el pasado. Los datos corroboran el hecho de 
que se pone en duda la palabra del/la maestro/a: "Como ahora que...investigamos ya todo..." (u.t. 68).

Entre las limitaciones escolares, el análisis de estos datos sugiere que los años de experiencia laboral en el mundo educativo podrían influir en la relación establecida con las familias y que, probablemente, cuantos más años se lleve en la docencia se acumulará mayor cansancio general en detrimento de la motivación por innovar en la búsqueda de cauces para la comunicación familiar.

Sin embargo, se podría concluir que, a pesar de que los/as informantes empleen gran parte de la entrevista en hablar sobre los numerosos obstáculos que hay actualmente en la relación Escuela-Familia, también ofrecen numerosas soluciones para que esa relación mejore.

En la figura 3, referente a la categoría "Soluciones" para fortalecer el vínculo Escuela-Familia, podemos ver que se subdivide en tres categorías: "Para la escuela", "Para las familias" y "Para escuela y familias". La mayor parte de las propuestas se refieren a la subcategoría "Para las familias", representando el $48 \%$ de los datos totales; mientras que el menor número de datos recogidos se refieren a la subcategoría de soluciones para ambos agentes educativos, representando el $22 \%$.

Todos estos datos, junto con las frecuencias y los porcentajes, pueden verse representados en la figura y tabla presentadas a continuación:

Soluciones para fortalecer el vínculo Escuela-Familia

口

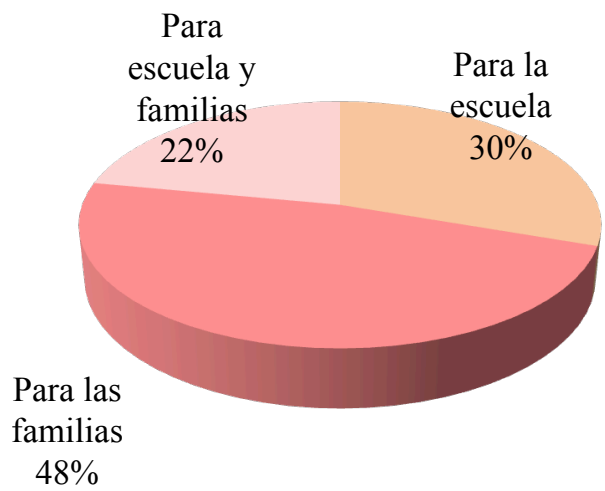

Figura 3. Distribución de las subcategoría de "Soluciones". Fuente: Elaboración propia.

Tabla 2.

Frecuencias y porcentajes de la categoría

\begin{tabular}{|c|}
\hline CATEGORÍA 5: SOLUCIONES \\
\hline Subcategoría: Para la escuela \\
\hline $\begin{array}{c}\text { Frecuencia (Unidades Textuales): } 33 \\
\text { Porcentaje: } 30 \%\end{array}$ \\
\hline Subcategoría: Para las familias \\
\hline $\begin{array}{c}\text { Frecuencia (Unidades Textuales): } 52 \\
\text { Porcentaje: } 48 \%\end{array}$ \\
\hline Subcategoría: Para escuela y familias \\
\hline $\begin{array}{c}\text { Frecuencia (Unidades Textuales): } 24 \\
\text { Porcentaje: } 22 \% \\
\end{array}$ \\
\hline
\end{tabular}

“Soluciones”. Fuente: Elaboración propia.

Numerosos informantes ofrecen la propuesta de una mayor apertura del centro educativo a la hora de realizar actividades en las que puedan intervenir las familias, así como una mayor participación de las familias. Uno/a de los informantes propone que se realicen actividades en el horario lectivo del/de la niño/a además de en el horario no lectivo. Serían: talleres, explicación al alumnado de su profesión por parte de los padres y madres, participación de las familias en la AMPA, la Escuela de Padres, excursiones... Con este tipo de encuentros (Torío, 2004) las familias podrían conocer la importante acción educativa que realiza el equipo docente. Dice un/a informante: "Yo creo que sí, que hacer más que nada un acercamiento para que se vea qué es lo que hacemos o sea cómo trabajamos, cómo nos involucramos en la enseñanza de los alumnos y...así a lo mejor también pues valorarían un poco más nuestro trabajo porque..." (u.t. 98-101).

Son varias las personas entrevistadas que coinciden en que el profesorado debe acercarse más a las familias mediante tutorías individuales y que la vocación del/de la maestro/a es fundamental en la relación con las familias.

Algunas soluciones ofrecidas para llevar a cabo por parte de las familias son:

-Que practiquen en casa todo lo que se lleva a cabo en la Escuela.

-Que se impliquen más, que no cuestionen la acción educativa de los/as maestros/as (y menos delante de los/as niños/as) o que en vez de criticar entre ellas, se dirijan al/la profesor/a: "Pues que la familias se involucraran más en la educación de sus hijos y que..." (u.t. 186-187). "Y las familias en vez de hablar más entre ellas,que hablen más directamente con la profesora" (u.t. 627-628).

También es relevante destacar que sería preciso que las familias facilitaran el trabajo del/de la docente y fueran flexibles a la hora de concertar una tutoría, que pusieran soluciones por su parte para poder tener esa reunión y saber cómo va su hijo/a. Varias de las personas entrevistadas exponen una idea muy importante: que la Escuela y la Familia deben llevar caminos paralelos, una vez definidas las funciones de cada agente educativo (De León, 2011), porque "la Escuela es una continuación de la Familia" (u.t. 284) y la relación Escuela-Familia debe estar caracterizada por la positividad, la fluidez, la comunicación y la cooperación entre ambos agentes educativos con el fin de favorecer al/a la niño/a.

Resulta importante recoger las soluciones para favorecer las buenas relaciones Escuela-Familia, que se han aportado a través de este trabajo de investigación. Pueden dividirse en tres categorías distintas:

-Soluciones para la Escuela:

Se pueden destacar los cursos de formación continua del profesorado sobre la buena relación EscuelaFamilia, cuyos objetivos serían: conocer la importancia de una buena relación con las familias; aprender diferentes maneras de trabajar y cooperar con ellas (aparte de las entradas y salidas, las reuniones...) y 
saber qué actitudes favorables deben tener con las familias y cuáles desfavorables no deben tener, con el fin de conseguir una relación positiva con las mismas.

-Soluciones para las familias:

Por un lado se señalan las ponencias informativas sobre la buena relación Escuela-Familia, que tendrían como objetivos principales: conocer qué y cómo (metodologías) se trabaja en la etapa de Educación Infantil; aprender qué es un/a maestro/a y cuáles son sus funciones; descubrir las ventajas de su colaboración con el centro educativo y analizar diferentes maneras de colaboración en el centro (AMPA, Escuela de Padres...).

Por otro lado destacan las grabaciones informales de los estudiantes en el aula, mediante las cuales, las familias podrían ver cómo son sus hijos/as en el aula, el gran vínculo afectivo que tienen con su maestro/a, todo lo que se trabaja en Educación Infantil..

-Soluciones para la Escuela y las familias:

En este último apartado se señalan las actividades conjuntas entre ambos agentes educativos, cuya finalidad sería conseguir un trabajo común y cooperativo. Serían actividades como: debates sobre diferentes temas relacionados con la educación, ponencias sobre los límites en la relación EscuelaFamilia o sobre los beneficios sobre el niño puede generar un contacto favorable entre ambas.

Ahora lo que cabe hacer es poner en práctica estas soluciones y mentalizarse de la importancia que tiene la relación Escuela-Familia en el desarrollo del protagonista en el proceso educativo, que es el mismo en ambos contextos (Ferradás, 2015), a pesar de que aún quede mucho camino para conseguir mejorar esta relación, como indican los datos "aunque todavía hay mucho trabajo por hacer por ambas partes" (u.t. 523). Lo importante es que la sociedad, la Escuela y las familias se mentalicen de que realmente es necesario y urgente continuar avanzando por esta senda.

\section{Referencias}

-Bolívar, A. (2006). Familia y escuela: dos mundos llamados a trabajar en común. Revista de Educación, 339, 119-146. Recuperado de www.revistaeducacion.mec.es/re339/re339a08.pdf -Cabrera, D., Funes, J. y Brullet, C. (2004) Alumnado, familias y sistema educativo. Barcelona: Octaedro.

-Dowling, J. y Pound, A. (1996). Intervenciones conjuntas con profesores, niños y padres en el marco escolar. En E. Dowling y E. Osborne (ed.), Familia y escuela. Una aproximación conjunta y sistémica a los problemas infantiles, pp. 95-113. Barcelona: Paidós.

-Ferradás, L. (2015). Relaciones escuelas-familias: la

laboriosa tarea de construir la cooperación. Revista Latinoamericana de Educación Infantil, 4 (2), 19-26. Recuperado http://redaberta.usc.es/reladei/documentos/volumenes/ volumen4_n2_completo.pdf

-García, M. L. (1996). Organización de la Escuela

Infantil. Madrid: Escuela Española.

-León, B. de (2011). XII Congreso Internacional de teoría de la Educación. La relación familia-escuela y su repercusión en la autonomía y responsabilidad de los niños/as. Recuperado el 2 de junio de 2016 de: https://extension.uned.es/archivos publicos/webex ac tividades/5385/repercusiones8.pdf

-Torío, S. (2004). Familia, Escuela y Sociedad. Aula

Abierta, 83, 36-52. Recuperado de https://dialnet.unirioja.es/descarga/articulo/1173765.p df 